\title{
Allergic bronchopulmonary aspergillosis treated successfully for one year with omalizumab
}

\author{
This article was published in the following Dove Press journal: \\ Journal of Asthma and Allergy \\ 7 November 2012 \\ Number of times this article has been viewed
}

\section{Jennifer Collins' \\ Gabriele deVos ${ }^{2}$ \\ Golda Hudes² \\ David Rosenstreich ${ }^{2}$}

'New York Eye and Ear Infirmary, New York, NY, ${ }^{2}$ Albert Einstein College of Medicine/Montefiore Medical Center, Bronx, NY, USA

Correspondence: Jennifer Collins New York Eye and Ear Infirmary 310 East 14th Street, 6th Floor, New York, NY 10003, USA

$\mathrm{Tel}+\mathrm{I} 6464387893$

Fax + I 6464387835

Email jscollin@yahoo.com
Background: Current therapy for allergic bronchopulmonary aspergillosis (ABPA) uses oral corticosteroids, exposing patients to the adverse effects of these agents. There are reports of the steroid-sparing effect of anti-IgE therapy with omalizumab for ABPA in patients with cystic fibrosis $(\mathrm{CF})$, but there is little information on its efficacy against ABPA in patients with bronchial asthma without $\mathrm{CF}$.

Objective: To examine the effects of omalizumab, measured by asthma control, blood eosinophilia, total serum immunoglobulin $\mathrm{E}$ ( $\mathrm{IgE}$ ), oral corticosteroid requirements, and forced expiratory volume spirometry in patients with ABPA and bronchial asthma.

Methods: A retrospective review of charts from 2004-2006 of patients treated with omalizumab at an academic allergy and immunology practice in the Bronx, New York were examined for systemic steroid and rescue inhaler usage, serum immunoglobulin E levels, blood eosinophil counts, and asthma symptoms, as measured by the Asthma Control Test (ACT).

Results: A total of 21 charts were screened for the diagnosis of ABPA and bronchial asthma. Four patients with ABPA were identified; two of these patients were male. The median monthly systemic corticosteroid use at 6 months and 12 months decreased from baseline usage. Total serum IgE decreased in all patients at 12 months of therapy. Pre-bronchodilator forced expiratory vital capacity at one second $\left(\mathrm{FEV}_{1}\right)$ was variable at 1 year of treatment. There was an improvement in Asthma Control Test (ACT) symptom scores for both daytime and nighttime symptoms.

Conclusions: Treatment with omalizumab creates a steroid-sparing effect, reduces systemic inflammatory markers, and results in improvement in ACT scores in patients with ABPA.

Keywords: allergic bronchopulmonary aspergillosis, omalizumab, asthma

\section{Introduction}

Allergic bronchopulmonary aspergillosis (ABPA), with variable prevalence in bronchial asthmatics, is a disease that is difficult to treat. ${ }^{1,2}$ Rosenberg-Patterson diagnostic criteria for ABPA include asthma, immediate skin reactivity to Aspergillus fumigatus or other Aspergillus species, a serum immunoglobulin (Ig) E level of $>417 \mathrm{IU} / \mathrm{mL}$, radiographic evidence of fleeting infiltrates or central bronchiectasis, and elevated serum levels of $A$. fumigatus specific IgE or $\mathrm{IgG}^{2}{ }^{2}$ Traditional therapy involves systemic corticosteroids and adjunctive antifungal treatment in an attempt to prevent irreversible lung damage. ${ }^{3-5}$ However, these treatments are often insufficient to control symptoms or lead to intolerable side effects. Since 2001, omalizumab (Xolair, Genentech, Novartis, South San Francisco, CA) has been a useful treatment for moderate to severe allergic asthma, but limited literature exists on its use in ABPA with bronchial 
asthma in patients without cystic fibrosis (CF). ${ }^{6-8}$ In 2007, we presented preliminary data on three patients with treatmentresistant ABPA (ie, those with corticosteroid-dependent disease), who were treated with omalizumab with improvement regarding quality of life symptoms, medication usage and pulmonary function testing. ${ }^{9}$ Recently, case reports of patients with cystic fibrosis and ABPA and adult asthmatics with ABPA have suggested that omalizumab, a recombinant anti-immunoglobulin E, might be effective for treating acute exacerbations and reducing systemic corticosteroid requirements. ${ }^{7-13}$ We sought to clarify whether omalizumab is a useful adjunctive therapy for adult asthmatics with ABPA.

\section{Methods Design}

We conducted a retrospective chart review of all asthmatic patients treated with omalizumab from 2004-2006 at two allergy and immunology clinics in the Bronx, NY, looking for those that fulfilled the diagnostic criteria for ABPA. All patients were treated by the same board certified allergist and immunologist before and after omalizumab therapy was initiated. The chart review was performed by two physicians (GH and JC). Charts were not screened for patients with cystic fibrosis as the clinical features were not present.

\section{Patients}

Patients were considered to have ABPA if they fulfilled all of the following criteria: a history of asthma, positivity to Aspergillus fumigatus on skin prick test or intradermal skin testing, a total serum immunoglobulin E (IgE) of $>417 \mathrm{IU} / \mathrm{mL}$, and radiographic findings of either fleeting chest $\mathrm{x}$-ray infiltrates or evidence of bronchiectasis on chest computed topography (CT). Patients were evaluated for stage of disease using the categories proposed by Patterson et al: acute (stage I), remission (stage II), exacerbation (stage III), corticosteroiddependent asthma (stage IV), and fibrotic (stage V). ${ }^{3}$

\section{Treatment}

All patients received omalizumab dosage and dosing intervals based on package insert guidelines, except patients with $\operatorname{IgE}$ levels $>700 \mathrm{IU} / \mathrm{L}$, who were given the maximum dosage of omalizumab, $375 \mathrm{mg}$ every 2 weeks. No dosing adjustments were made throughout the treatment period.

\section{Outcome measures}

We collected data at three points: baseline (4 weeks prior to starting omalizumab), 6 months (months 1-6), and 12 months (months 7-12) after treatment with omalizumab. We collected data on: (1) medication usage, including systemic steroid and rescue medication use, (2) serum $\mathrm{IgE}$ at baseline and after 12 months of treatment, (3) eosinophil levels at baseline and after 12 months of treatment, and (4) quality of life symptoms at baseline, 6 months, and 12 months of treatment. Values after 6 and 12 months of treatment were compared to baseline values. Quality of life scores were taken from self-reported answers to the Asthma Control Test (ACT). ${ }^{14}$

\section{Symptom scores}

Daytime symptoms and nighttime symptoms were rated as none of the time, some of the time, most of the time, and all of the time. These answers were converted into numerical scores of $0,1,2$, or 3 , respectively. Rescue inhaler usage was based on patient reporting at baseline, 6 months, and 12 months of treatment. Systemic steroid usage was based on patient reports collected from the medical records at baseline, 6 months, and 12 months of treatment. Average monthly steroid use was calculated based on an assumption of a 30-day month. For example, if a patient was taking a total of $30 \mathrm{mg}$ of corticosteroids daily for 3 months and $10 \mathrm{mg}$ daily for 3 months $(30 \mathrm{mg} \times 30$ days $\times 3$ months $)+(10 \mathrm{mg}$ $\times 30$ days $\times 3$ months $) / 6$ months $=600 \mathrm{mg}$, the monthly average would be $600 \mathrm{mg}$.

\section{Statistical Analysis}

ANOVA and paired $t$-tests were performed using Microsoft Excel. ${ }^{15}$

\section{Results}

\section{Patient demographics and clinical characteristics at baseline}

Twenty-one charts were reviewed and four patients satisfying the diagnostic criteria for ABPA were identified. Patient demographics and clinical characteristics are summarized in Table 1. Mean age was 50.5 years (range 44-58) and 50\% were male. All patients were stage IV ABPA (corticosteroid-dependent). Patients, on average, had been followed for 16 months by the same allergist/immunologist and/or pulmonologist before starting omalizumab. Corticosteroid doses were stable prior to initiating omalizumab. All records from both physicians were reviewed. All four patients had treatment failure with systemic steroids; two had treatment failure with itraconazole. All patients had positive skin prick and/or intradermal testing to A. fumigatus or RAST testing. Baseline medications included inhaled corticosteroids and long acting beta-agonists combinations, leukotriene receptor antagonists, and leukotriene inhibitors. 


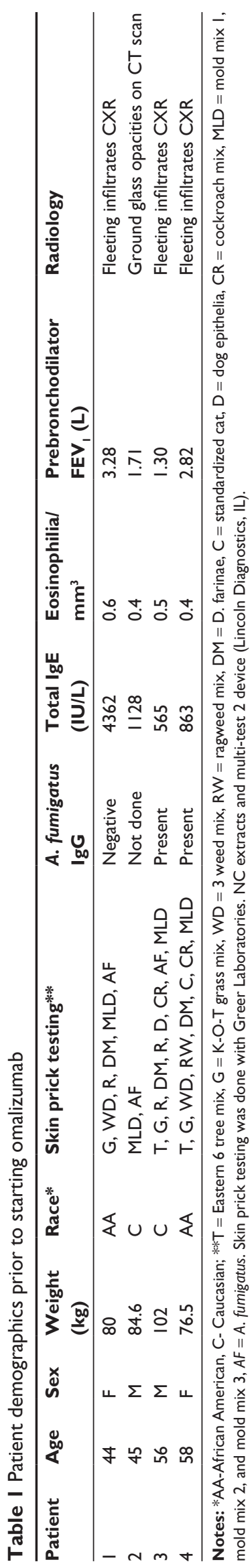

All baseline medications were continued throughout treatment. Patient 2 had ground glass opacities on CT scan; the other patients $(1,3$, and 4$)$ had evidence of fleeting infiltrates on chest radiography or chest CT. Six months prior to initiating omalizumab, the average serum IgE was $1730 \mathrm{IU} / \mathrm{L}$ $($ range $=565-4362 \mathrm{IU} / \mathrm{L})$; the average pre-bronchodilator $\mathrm{FEV}_{1}$ at baseline was $2.28 \mathrm{~L}$ (range 1.3-3.28 L), and the average eosinophil level was $0.48 / \mathrm{mm}^{3}\left(0.4-0.6 / \mathrm{mm}^{3}\right)$. All patients were treated with $375 \mathrm{mg}$ every two weeks.

\section{Changes in medication use}

Average total monthly systemic steroid use after 6 months and 12 months of omalizumab decreased in all patients (Figure 1). Average monthly steroid use at baseline, 6 months, and 12 months was $1002 \mathrm{mg}, 506 \mathrm{mg}$, and $206 \mathrm{mg}$ $(P=0.01)$. There was a $67 \%, 40 \%, 48 \%$, and $50 \%$ reduction in total monthly corticosteroid use from baseline to 6 months, and $20 \%, 99 \%, 14 \%$, and $58 \%$ reduction in total monthly steroid use from 6 months to 12 months in patients 1, 2, 3, and 4 , respectively.

Rescue inhaler use by the patients was variable. Patient 1 did not use any rescue inhaler, while patient 2 used it often. In contrast to decreased oral corticosteroid use, rescue inhaler use only changed significantly in the one high rescue inhalerusing patient (patient 2). In this patient, at 6 and 12 months after initiation of omalizumab, average weekly rescue inhaler use decreased from 49 times per month to 0 ; there was no significant change in usage by the other patients.

\section{Changes in asthma symptoms and lung function}

Along with the decrease in oral corticosteroid use, daytime and nighttime asthma symptoms, as measured by the ACT, improved after omalizumab. Patients 1, 3, and 4 reported significant improvement in both daytime and nighttime symptom ACT scores (Figures 2A and B). There was no

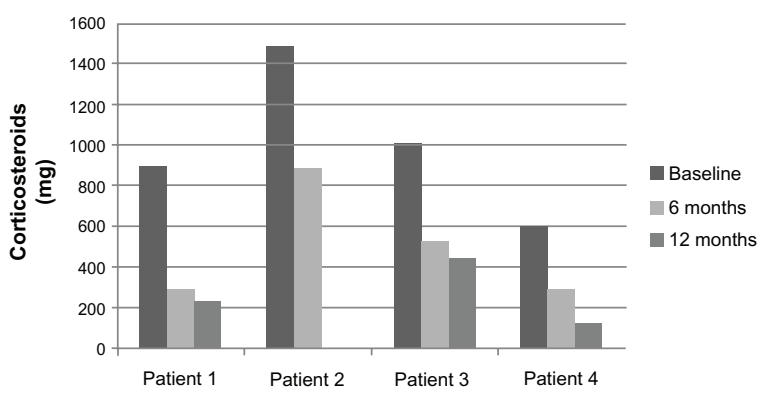

Figure I Average monthly systemic steroid use based on patient records 6 months prior to initiation of omalizumab, at 6 month point and at 12 months of therapy $(P=0.01)$. 
consistent effect on pre-bronchodilator $\mathrm{FEV}_{1}$ at 12 months (Figure 3).

\section{Changes in inflammatory markers}

Total blood eosinophil counts and serum IgE were measured before and after approximately 1 year of treatment with omalizumab. Eosinophil counts decreased after 12 months of treatment in three of the patients (patients 1, 3, and 4). Mean eosinophil counts at 12 months decreased by $38 \%$ to $0.2 / \mathrm{mm}^{3}$ (range $0.1-0.5 / \mathrm{mm}^{3}$ ). These changes approached statistical significance $(P=0.06)$ (Figure 4$)$.

Total serum IgE at 12 months of treatment decreased in all four patients, going from a mean of 1730 IU/L at baseline (range 565-4362 IU/L) to a mean of $914 \mathrm{IU} / \mathrm{L}$ (range 466-1638 IU/L) after 12 months of treatment (Figure 5). However, these changes were not significant $(P=0.40)$.

\section{Discussion}

These results indicate that omalizumab treatment for 12 months may offer a corticosteroid-sparing treatment option and improvement in asthma symptoms, as measured by the ACT. There was also a concomitant reduction in two inflammatory markers: blood eosinophilia and total serum IgE levels. In ABPA, symptoms and inflammatory marker levels are significantly improved by oral corticosteroid treatment, ${ }^{16,17}$ so these observed reductions in asthma symptoms and inflammatory markers are even more meaningful, since they were associated with a decrease in oral corticosteroid use by all four patients.

While no data exists on the incidence of adverse effects from oral corticosteroids in patients with ABPA, the side effects of increased diabetes, cataracts/glaucoma, hypertension, risk of fractures, immunosuppression, and gastrointestinal complaints are important concerns for patients on long term systemic corticosteroids. Therefore, the corticosteroid-sparing effect of omalizumab in these patients is a clinically relevant finding.

There are other reports of improved control of ABPA in adult asthmatics with the use of omalizumab. Perez-de-llano et al followed 18 patients with ABPA (16 adult asthmatics with ABPA and 2 with CF and ABPA) for a median of 16 weeks. They showed improvements in daily asthma symptoms, improved $\mathrm{FEV}_{1}$, and a reduction in oral corticosteroid usage. $^{7}$ Tillie-Leblond et al followed 16 adult asthmatics with ABPA for 12 months and showed a reduction in asthma exacerbations and reduced oral corticosteroid usage. ${ }^{8}$

Unlike previously described patients with cystic fibrosis and $\mathrm{ABPA},{ }^{10-13}$ the improvement in $\mathrm{FEV}_{1}$ and quality of life symptom scores in our patients were not as immediate or dramatic. In reports on the use of omalizumab in patients with cystic fibrosis and ABPA, omalizumab was administered in most cases during an acute exacerbation and continued for up to 12 months. These patients may have had a better baseline $\mathrm{FEV}_{1}$ or there may have been a different pathophysiology of ABPA and omalizumab in patients with cystic fibrosis and ABPA as compared to ABPA and bronchial asthma.

The significance of the observed decrease in serum $\mathrm{IgE}$ is unclear. Serum $\mathrm{IgE}$ is typically used as a marker of disease exacerbation in ABPA, with a doubling indicating an exacerbation. Omalizumab specifically binds to the same portion of the C\&3 domain of $\operatorname{IgE}$ involved in binding to the high-affinity IgE receptor, thus blocking binding of specific IgE on mast cells and basophils, preventing degranulation. During treatment, free IgE levels in serum decline rapidly while bound anti-IgE-IgE complexes result in elevations of total IgE. Because of this phenomenon, serum IgE levels are generally not considered to be a reliable marker of a clinical

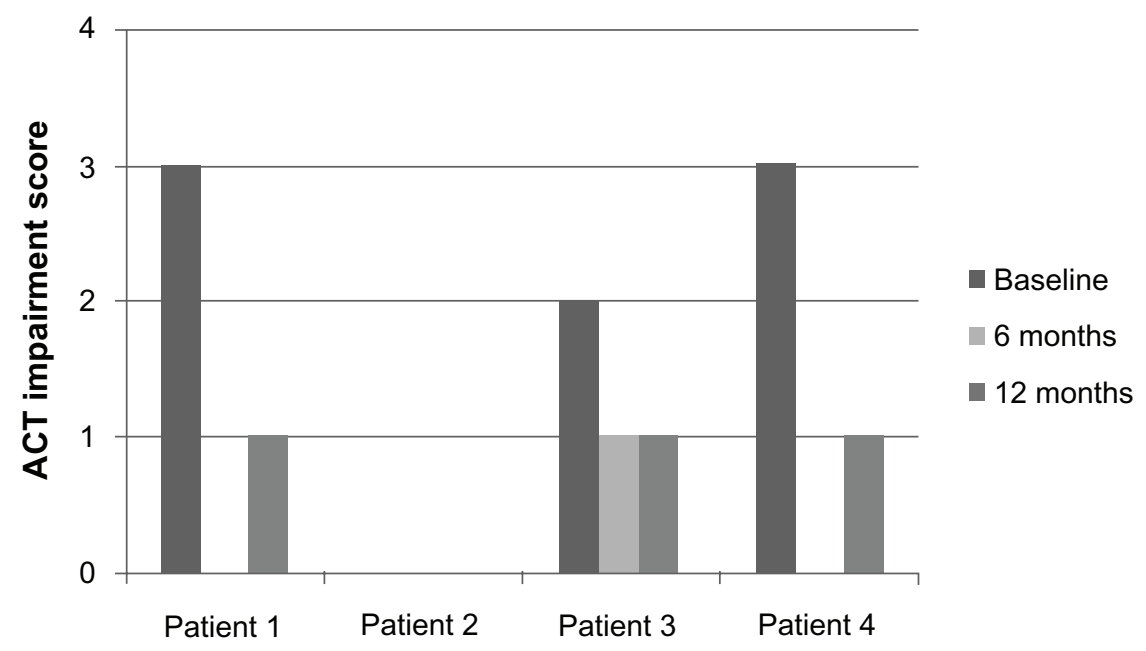

Figure 2A ACT daytime symptom impairment scores at baseline, 6 months, and 12 months of treatment with omalizumab. 


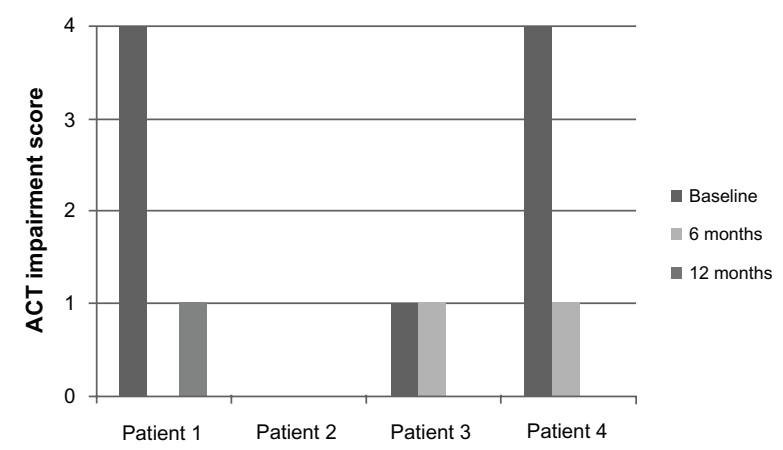

Figure 2B ACT nighttime scores at baseline, 6 months, and 12 months of treatment with omalizumab.

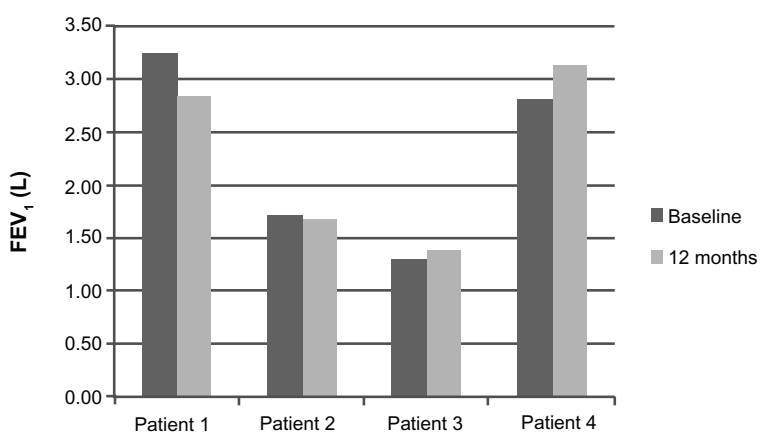

Figure 3 Prebronchodialator FEV, (L) values at baseline and at 12 months.

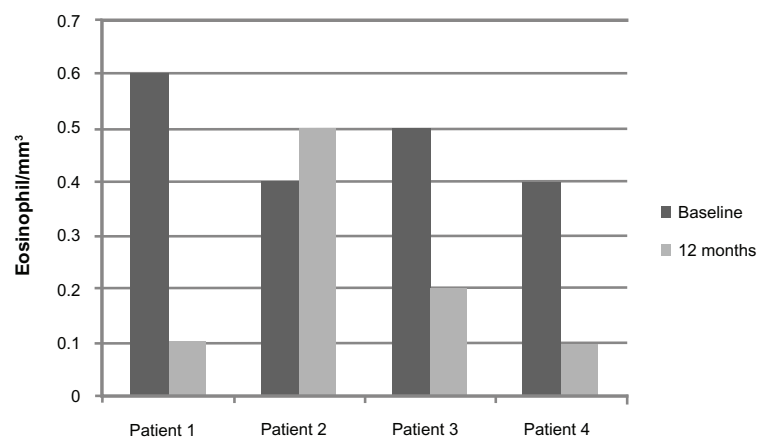

Figure 4 Eosinophil levels at baseline and 12 months of treatment $(P=0.06)$.

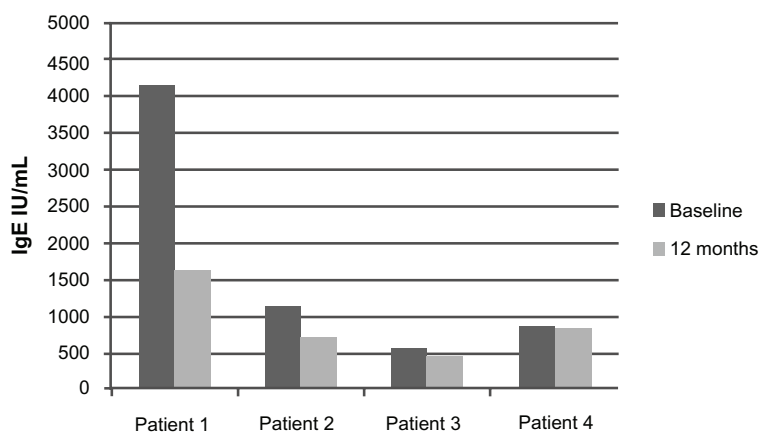

Figure 5 Total serum IgE from baseline to 12 months of treatment with omalizumab $(P=0.4)$. response once therapy is initiated. ${ }^{17,18}$ However, in patients with severe asthma treated with omalizumab, Slavin et al report positive correlations between asthma symptoms and total serum IgE levels. ${ }^{19}$ In another report, Lin et al also suggest that serum IgE in patients treated with omalizumab is still an important marker of disease activity. ${ }^{20}$ It is unknown whether the reduction in total serum IgE and eosinophilia is part of the natural course of ABPA or a marker for successful treatment with omalizumab. The decrease in eosinophil levels is consistent with what has been previously reported as an effect of omalizumab.

Using a cutoff total IgE value of $>417 \mathrm{kU} / \mathrm{L}$, rather than the more stringent value of $1000 \mathrm{kU} / \mathrm{L}$, as proposed by Agrawal, may have led to an over diagnosis of ABPA in our study population..$^{21}$ It is difficult to know what the true $\operatorname{IgE}$ level was, given that all patients were on oral corticosteroids at the time of measurement.

ABPA is a chronic disease with episodes of remission and exacerbation. Our treatment period of 1 year may have coincided with periods of disease quiescence. Patients 1 , 3 , and 4 are currently cared for by the same allergist and immunologist. Patient 3 continues omalizumab therapy. He required one burst of corticosteroids in December 2011. Patients 1 and 4 stopped omalizumab after 1 year, secondary to problems with insurance coverage. Both are currently on oral corticosteroids to manage their symptoms. Patient 1 now requires prednisone $5-20 \mathrm{mg}$ daily to control symptoms. Patient 4 is maintained on $10 \mathrm{mg}$. Patient 2 was lost to follow up after 1 year; efforts to reach him were unsuccessful.

Questions remain about the effective dosage and the utility of omalizumab in asthmatics with ABPA. Patients 1,2 , and 4 had higher levels of baseline IgE $(<700 \mathrm{IU} / \mathrm{L})$ than is recommended for omalizumab therapy. Patients with such serum levels may require higher doses of omalizumab to achieve complete reduction of symptoms.

One use of systemic steroids in ABPA is to prevent the progression of disease to permanent fibrosis of the lungs. It is unclear if omalizumab has a similar effect. Our patients did not have repeat chest x-rays or CTs after the initiation of omalizumab to determine whether there was resolution or progression of the radiographic findings, but it would be interesting to determine whether there was improvement in this disease marker.

Omalizumab seems to represent a potential steroidsparing, alternative treatment for patients with ABPA. However, we recognize that interpretation of these results is limited by the inherent problems associated with a retrospective chart review, by a lack of complete data 
collection, and by the small number of patients studied. Future studies including randomized double blind placebo trials are needed to clarify the true beneficial effects of omalizumab in the treatment of ABPA.

\section{Acknowledgments}

Dr Jennifer Collins, MD organized the data and was the primary author for this paper. Dr G deVos, MD, MS contributed to statistical analysis and revisions. Drs G Hudes, MD, PhD and D Rosenstreich, MD provided input into the organization of this paper, chart review, editorial advice, and information on patients with allergic bronchopulmonary aspergillosis. Dr Gopei Yu provided statistical advice. Drs Vivian Chou and Anita Gewurz provided editorial advice and information regarding one of their patients with ABPA who was treated with omalizumab.

\section{Disclosure}

The authors report no conflicts of interest in this work.

\section{References}

1. Agarwal R, Agarwal AN, Gupta D, Jindal SK. Aspergillus hypersensitivity and allergic bronchopulmonary aspergillosis in patients with bronchial asthma: systematic review and meta-analysis. Int J Tuberc Lung Dis. 2009;8:936-944.

2. Greenberger PA, Patterson R. Allergic bronchopulmonary aspergillosis and the evaluation of the patient with asthma. J Allergy Clin Immunol. 1988;81:646-650.

3. Patterson R, Greenberger PA, Radin RC, Roberts M. Allergic bronchopulmonary aspergillosis: staging as an aid to management. Ann Intern Med. 1982;96(3):286-291.

4. Wark PA, Hensley MJ, Saltos N, et al. Anti-inflammatory effect of itraconazole in stable allergic bronchopulmonary aspergillosis: a randomized controlled trial. J Allergy Clin Immunol. 2003;111(5):952-957.

5. Judson MA, Stevens DA. Current pharmacotherapy of allergic bronchopulmonary aspergillosis. Expert Opin Pharmacother. 2001;2(7): 1065-1071.

6. Allergic Bronchopulmonary Aspergillosis [medical letter]. South San Francisco, CA: Genetech Novartis; 2011.
7. Pérez-de-Llano L, Vennera M, Parra A, et al. Effects of omalizumab in Aspergillus-associated airway disease. Thorax. 2011;66: 539-540.

8. Tillie-Leblond I, Germaud P, Leroyer C, et al. Allergic bronchopulmonary aspergillosis and omalizumab. Allergy. 2011;66: 1254-1256.

9. Collins J, Hudes G, Rosenstreich D. Allergic Bronchopulmonary Aspergillosis Treated Successfully with Omalizumab: Three Case Reports [oral presentation]. Ann Allergy Asthma Immunol. 2008;100(Suppl 1): A3-A97.

10. Kanu A, Patel K. Treatment of allergic bronchopulmonary aspergillosis (ABPA) in CF with anti-IgE antibody (omalizumab). Pediatr Pulmonol. 2008;43(12):1249-1251.

11. Lebecque P, Leonard A, Pilette C. Omalizumab for treatment of ABPA exacerbations in cystic fibrosis patients. Pediatr Pulmonol. 2009;44:516.

12. Van der Ent CK, Hoekstra H, Rijkers GT. Successful treatment of allergic bronchopulmonary aspergillosis with recombinant anti-IgE antibody. Thorax. 2007;62(3):276-277.

13. Zirbes JM, Milla CE. Steroid-sparing effect of omalizumab for allergic bronchopulmonary aspergillosis and cystic fibrosis. Pediatr Pulmonol. 2008;43(6):607-610.

14. Nathan RA, Sorkness CA, Kosinski M, et al. Development of the asthma control test: a survey for assessing asthma control. J Allergy Clin Immuno. 2004;113(1):59-65.

15. Excel (Part of Microsoft Office) [computer program]. Microsoft; 2007.

16. Marchant JL, Warner JO, Bush A. Rise in total IgE as an indicator of allergic bronchopulmonary aspergillosis in cystic fibrosis. Thorax. 1994;49(10):1002.

17. Ricketti AJ, Greenberger PA, Patterson R. Serum IgE as an important aid in management of allergic bronchopulmonary aspergillosis. J Allergy Clin Immuno. 1984;74(1):68.

18. Busse W, Corren J, Lanier BQ, et al. Omalizumab, anti-IgE recombinant humanized monoclonal antibody, for the treatment of severe allergic asthma. J Allergy Clin Immunol. 2001;108(2):184-190.

19. Slavin RG, Ferioli C, Tannenbaum SJ, Martin C, Blogg M, Lowe PJ. Asthma symptom re-emergence after omalizumab withdrawal correlates well with increasing IgE and decreasing pharmacokinetic concentrations. J Allergy Clin Immunol. 2009;123(1):107-113. e3.

20. Lin RY, Sethi S, Bhargave GA. Measured immunoglobulin E in allergic bronchopulmonary aspergillosis treated with omalizumab. J Asthma. 2010;47(8):942-945.

21. Agrawal R. Allergic bronchopulmonary aspergillosis. Chest. 2009; 135(3):805-826.
Journal of Asthma and Allergy

\section{Publish your work in this journal}

The Journal of Asthma and Allergy is an international, peer-reviewed open-access journal publishing original research, reports, editorials and commentaries on the following topics: Asthma; Pulmonary physiology; Asthma related clinical health; Clinical immunology and the immunological basis of disease; Pharmacological interventions and

\section{Dovepress}

new therapies. Issues of patient safety and quality of care will also be considered. The manuscript management system is completely online and includes a very quick and fair peer-review system, which is all easy to use. Visit http://www.dovepress.com/testimonials.php to read real quotes from published authors. 